\title{
Induction and consolidation of calcium-based homo- and heterosynaptic potentiation and depression
}

\author{
Yinyun Li, Tomas Kulvicius, Christian Tetzlaff* \\ From 24th Annual Computational Neuroscience Meeting: CNS*2015 \\ Prague, Czech Republic. 18-23 July 2015
}

Synaptic plasticity serves as the physiological foundation for learning and memory [1]. While homosynaptic plasticity is associative learning or Hebbian-type plasticity, heterosynaptic plasticity reflects the synaptic change without direct stimulation, i.e. non-associative plasticity [2]. However, heterosynaptic plasticity is an important mechanism preventing run-away synaptic dynamics and offers a potential mechanism to understand memory allocation [2,3]. Experimental results show that the induction of heterosynaptic plasticity as well as homosynaptic plasticity depends on the postsynaptic calcium concentration [4]. We propose that heterosynaptic plasticity can be induced by the postsynaptic calcium dynamics which can be triggered by the back propagation of action potentials.

However, homosynaptic plasticity has an early-phase $(<3$ hours) and a late-phase state ( $>8$ hours) [1]. Experiments show that an early-phase synaptic change can be transferred to a late-phase by the mechanisms of "synaptic tagging and consolidation" (STC) [5,6]: (i) the changed synapse get tagged and (ii) a strong activation enables in the postsynaptic neuron the synthesis of plasticity-related proteins (PRP) which are transmitted back to the tagged synapse[5,6]. We propose that the same STC mechanism consolidating homosynaptic changes are also able to consolidate heterosynaptic changes.

We combine a history spiking-dependent neuron [7] with calcium-based synaptic plasticity rule [8] and synaptic consolidation mechanism [9] to understand: (i) the mechanisms of inducing heterosynaptic plasticity by which the inactive synapse can change its weight

\footnotetext{
* Correspondence: tetzlaff@phys.uni-goettingen.de
III Institute of Physics, Department of Computational Neuroscience, Georg-

* Correspondence: tetzlaff@phys.uni-goettingen.de
III Institute of Physics, Department of Computational Neuroscience, GeorgAugust-University Göttingen, Bernstein Center for Computational Neuroscience, Göttingen, 37077, Germany
}

through the postsynaptic calcium level triggered by the back propagation of the shared neuron; and (ii) of the consolidation of heterosynaptic changes based on the synaptic tagging and consolidation principle. For instance, a strong stimulus transmitted by a group of synapses induces and consolidates by the postsynaptic neuron heterosynaptic changes at other, unrelated synapses. Our study provides a further step of understanding how several mechanisms interact with each other to enable the formation of computational important long-term changes or memories.

\section{Acknowledgements}

This research is funded by from the European Communities Seventh Framework Program FP7/2007-as well as from the Germany Ministry of Science Grant to the Göttingen Bernstein Center for Computational

\section{Published: 18 December 2015}

\section{References}

Abraham WC: How long will long term potentiation last? Phil. Trans. $R$. Soc. Lond. B 2003, 358:735-744.

2. Chistiakova M, Bannon NM, Bazhenov M, Volgushev M: Heterosynaptic plasticity: multiple mechansims and muliple roles. Neuroscientist 2014, 20(5):483-498.

3. Rogerson T, Cai DJ, Frank A, Sano Y, Shobe J, et al: Synaptic tagging during memory allocation. Nat Rev Neurosci 2014, 15:157-169.

4. Malenka RC, Kauer JA, Zucker RS, Nicoll RA: Postsynaptic calcium is sufficient for potentiation of hippocampal synaptic transmission. Science 1988, 242:81-84

5. Frey U, Morris R GM: Synaptic tagging and long-term potentiation. Nature 1997, 385:533-536

. Sajikumar S, Navakkode S, Frey JU: Identification of compartment-and Process-Specific Molecules Required for "Synaptic Tagging" during LongTerm Potentiation and Long-Term Depression in Hippocampal CA1. J Neurosci 2007, 27(19):5068-5080.

7. Yamauchi S, Kim H and Shinomoto S: Elemental spiking neuron model for reproducing diverse firing patterns and predicting precise firing times. Front in Comput neurosci 2011, 5(42):1-15. 
8. Graupner M, Brunel N: Calcium-based plasticity model explains sensitivity of synaptic changes to spike pattern, rate and dendritic location. PNAS 2012, 109(10):3991-3996.

9. Clopath C, Ziegler L, Vasilaki E, Buesing L, Gerstner W: Tag-TriggerConsolidation: A Model of Early and Late Long-Term-Potentiation and Depression. PLOS CB 2008, 4(12):e1000248.

doi:10.1186/1471-2202-16-S1-P252

Cite this article as: Li et al:: Induction and consolidation of calciumbased homo- and heterosynaptic potentiation and depression. BMC Neuroscience 2015 16(Suppl 1):P252.

Submit your next manuscript to BioMed Central and take full advantage of:

- Convenient online submission

- Thorough peer review

- No space constraints or color figure charges

- Immediate publication on acceptance

- Inclusion in PubMed, CAS, Scopus and Google Scholar

- Research which is freely available for redistribution

Submit your manuscript at www.biomedcentral.com/submit
C) Biomed Central 